\title{
Carcinoma escamocelular de pulmón
}

\section{Squamous cell carcinoma of the lung}

Carlos García, MD. ${ }^{(1)}$; SARa Rodríguez-TAKeuchi, MD. ${ }^{(2)}$; HÉctor Escobar, MD. ${ }^{(2)}$

${ }^{(1)}$ Especialista en Radiología e Imágenes Diagnósticas, Fundación Valle de Lili. Facultad de Ciencias de la Salud, Universidad Icesi. Cali, Colombia.

${ }^{(2)}$ Residente de Radiología e Imágenes Diagnósticas, Fundación Valle del Lili. Facultad de Ciencias de la Salud, Universidad ICESI. Cali, Colombia.

Correspondencia: Carlos García, correo electrónico: medgarc98@yahoo.com Recibido: 03/10/16. Aceptado: 30/10/16.

\section{Introducción}

El carcinoma escamocelular representa el $30 \%$ de los tumores pulmonares (1). En el 2015 la Organización Mundial de la Salud (OMS) publicó una actualización de la clasificación de este tumor incluyendo cuatro subtipos histológicos: queratinizante, no-queratinizante, basaloide e in situ (2).

\section{Radiografía de tórax}

La mayoría de veces estos tumores se localizan en forma central en el pulmón dentro de los bronquios principales, lobares o segmentarios en aproximadamente dos tercios de los casos (3), comúnmente causan colapso pulmonar (4) (figura 1) y pueden crecer por encima de $4 \mathrm{~cm}$, con un diámetro promedio al momento del diagnóstico de $2,5 \mathrm{~cm} \mathrm{(5,}$ $6)$; adicionalmente, no hay una característica típica de los bordes de la lesión los cuales pueden ser lobulados, espiculados o lisos (figura 2). Por su parte, se encuentra necrosis central y cavitación hasta en un 15\% de los casos $(3,7)$, y la pared de la cavitación típicamente es gruesa e irregular y no presenta niveles hidroaéreos $(3,8)$.

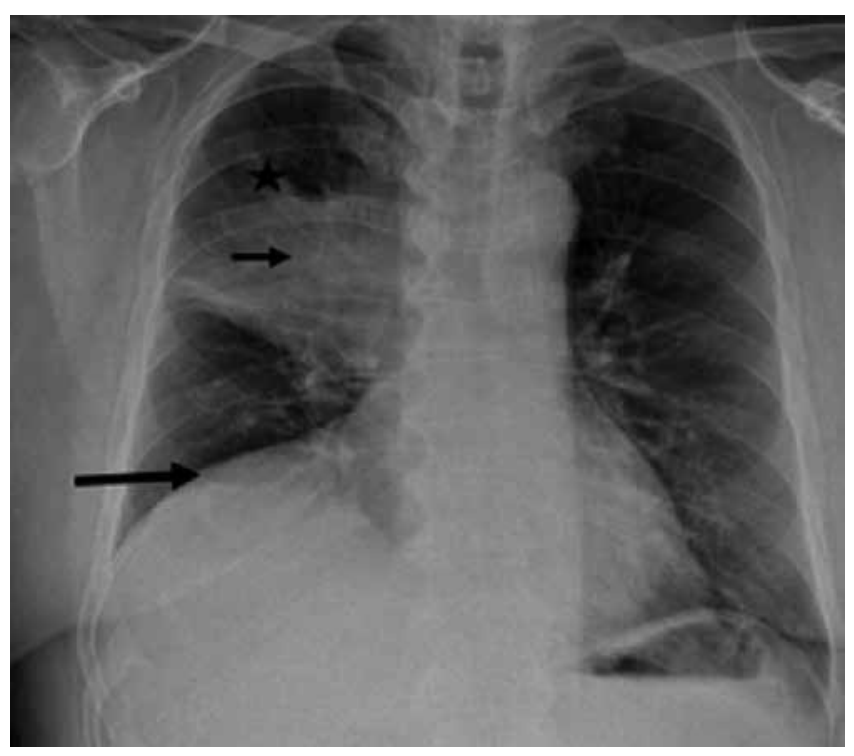

Figura 1. Radiografía de tórax en proyección postero-anterior correspondiente a paciente de 68 años de edad con antecedente de consumo de tabaco. Se evidencia masa de densidad homogénea en la región parahiliar derecha con atelectasia del lóbulo inferior derecho (flecha corta) y elevación del hemidiafragma derecho (flecha larga) con atelectasias subsegmentarias del lóbulo superior (estrella negra). 


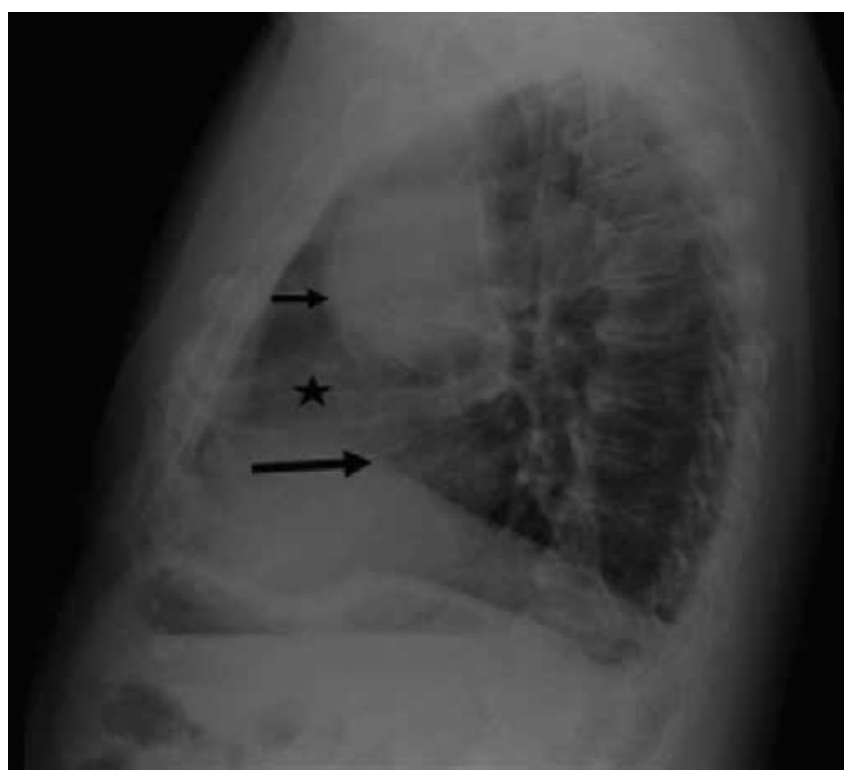

Figura 2. Radiografía lateral del paciente anterior que muestra masa de densidad homogénea ubicada en el mediastino anterior, de bordes lisos y definidos (flecha corta) con atelectasia del lóbulo medio (flecha gruesa) que ocasiona elevación del hemidiafragma derecho (flecha larga). La biopsia reportó carcinoma de pulmón de células no pequeñas, tipo escamocelular moderadamente diferenciado.

La manifestación típica del carcinoma escamocelular es la obstrucción endobronquial parcial o total, que con frecuencia puede conducir a neumonía postobstructiva; por tanto, todos los casos de neumonía en los adultos deben ser seguidos a través del tiempo, hasta la resolución radiológica completa de los infiltrados, para excluir una lesión subyacente causante de la neumonía, en estos casos postobstructiva $(3,6)$.

Dada la presencia de la masa central, el lóbulo es incapaz de colapsar por completo y puede producirse un contorno abultado de la atelectasia a causa del tumor primario, que puede dar la apariencia radiológica del signo de "la S de Golden" $(3,6)$.

Aproximadamente, un tercio de los carcinomas escamocelulares son periféricos y aparecen como un nódulo o masa pulmonar solitaria y su ubicación periférica es la causa más común del síndrome de Pancoast, caracterizado clínicamente por dolor y atrofia de los músculos de la extremidad superior ipsilateral debido al compromiso del plexo branquial y al síndrome de Horner dado por compromiso de la cadena simpática y del ganglio estrellado.

La extensión hiliar o mediastinal del carcinoma escamocelular puede causar ensanchamiento mediastinal, aumento del ángulo de la carina, pérdida de la concavidad de la ventana aortopulmonar y crecimiento del hilio en forma uni o bilateral en la radiografía de tórax (6).

\section{Tomografía computarizada}

La tomografía facilita una mejor caracterización del carcinoma escamocelular dado que este tumor puede pasar oculto en las radiografías (9). La particularidad más importante es su localización central por compromiso de los bronquios lobares o segmentarios (figura 2). La identificación de una masa central está presente en el $61 \%$ de los casos (10).

Los carcinomas escamocelulares se presentan como una masa de atenuación sólida y márgenes irregulares (11). Se cree que los contornos irregulares son consecuencia de la contracción de la porción central del tumor asociado a una respuesta desmoplásica por el crecimiento del mismo (10). Estas lesiones disminuirán la luz bronquial e infiltrarán su pared, de ahí que no sea infrecuente hallar atelectasias obstructivas segmentarias o lobares (10); esta última está presente hasta en el 56\% de los casos (10).

Estos tumores pueden tener una cavitación central hasta en un 15\% (figura 3), característica importante para diferenciarlo de otros tumores broncogénicos. Así mismo, es común visualizar la conexión de la cavitación central con la luz del bronquio $(3,10)$.

Las calcificaciones son infrecuentes en los tumores primarios de pulmón; se observan aproximadamente en $6 \%$ de los casos; los subtipos histológicos que más presentan calcificaciones son el carcinoma de célula pequeña y el carcinoma escamocelular (figura 4).

A diferencia del adenocarcinoma de pulmón, en el carcinoma escamocelular las metástasis tienden a 


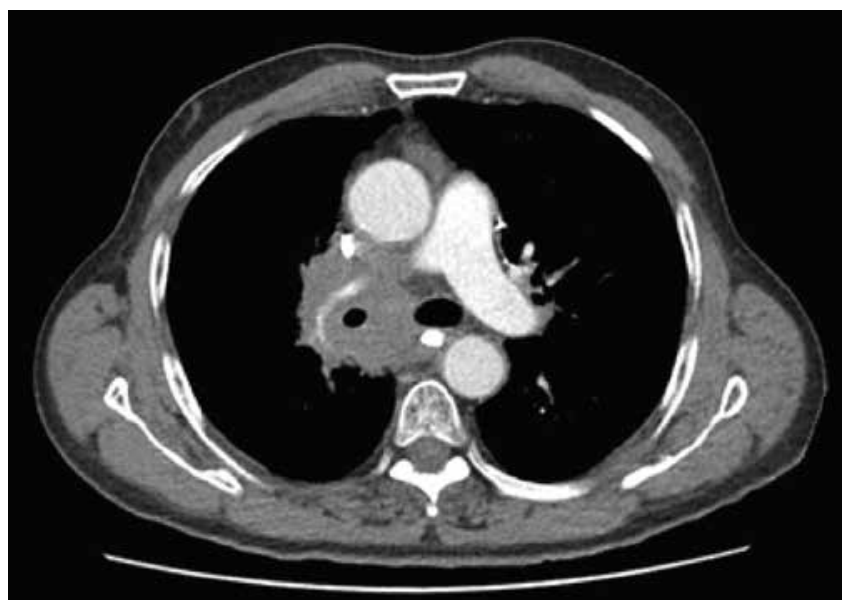

Figura 3. Masa hiliar derecha, de bordes espiculados, con densidad de tejidos blandos, que ocasiona disminución de la luz del bronquio fuente derecho y de la arteria pulmonar derecha.

ser una manifestación radiológica tardía (1). La principal vía de diseminación del carcinoma escamocelular de pulmón es la extensión local a ganglios linfáticos hiliares o mediastinales (9). La diseminación linfangítica con engrosamiento liso o nodular de los septos interlobulillares, subpleurales y peribroncovasculares no es una característica frecuente en el carcinoma escamocelular, y su presencia debe hacer sospechar un adenocarcinoma.

\section{Bibliografía}

1. Munden RF, Bruzzi J. Imaging of non-small cell lung cancer. Radiol Clin North Am. 2005;43(3):467-80.

2. Travis WD, Brambilla E, Nicholson AG, Yatabe Y, Austin JH, Beasley MB, et al. The 2015 World Health Organization Classification of Lung Tumors: Impact of Genetic, Clinical and Radiologic Advances Since the 2004 Classification. J Thorac Oncol. 2015;10(9):1243-60.

3. Rosado-de-christenson ML, Templeton PA, Moran CA. Bronchogenic carcinoma: radiologic-pathologiccorrelation. Radiographics. 1994;14(2):429-46.

4. Byrd RB, Miller WE, Carr DT, Payne WS, Woolner LB. The roentgenographic appearance of squamous cell carcinoma of the bronchus. May Clin Proc. 1968;43:327-32.

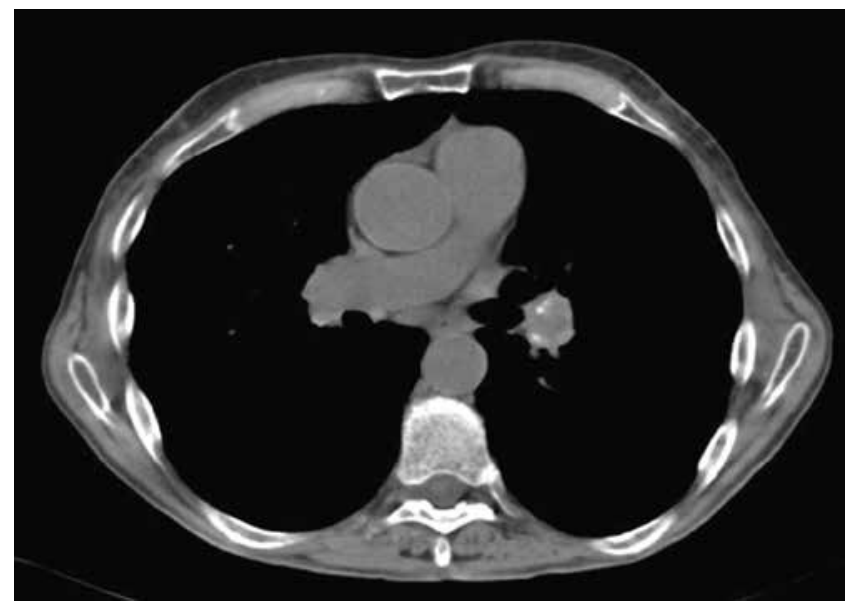

Figura 4. Nódulo hiliar izquierdo con centro necrótico y calcificaciones periféricas lineales.

5. Armstrong P. Neoplasms of the lungs, airways and pleura. In: Armstrong P, Wilson AG, Dee P, Hansell DM, eds. Imaging of Diseases of the Chest. 3rd. edition. London: Mosby (Harcourt); 2000. p. 305-401.

6. Rosado de Christenson ML, Carter B. Speciality imaging: thoracic neoplasm. 2nd. Ed. Sec 2. Philadelphia, PA: Amirsys/ Elsevier. 2nd Ed. 2016.

7. Chaudhuri MR. Primary pulmonary cavitating carcinomas. Thorax. 1973;28:354-66.

8. Mcloud T, Boiselle Pm. thoracic radiology: the requisites. 2nd. ed. Chapter 11. Philadelphia, PA: Mosby Elsevier 2nd de. 2010 Chapter 1; 2010. p. 260-2.

9. Saida Y, Kujiraoka Y, Akaogi E, Ogata T, Kurosaki Y, Itai Y. Early squamous cell carcinoma of the lung: CT and pathologic correlation. Radiology. 1996;201(1):61-5.

10. Sokhandon F, Sparschu RA, Furlong JW. Best cases from the AFIP: bronchogenic squamous cell carcinoma. Radiographics. 2003;23(6):1639-43.

11. Lindell RM, Hartman TE, Swensen SJ, Jett JR, Midthun DE, Tazelaar HD, et al. Five-year lung cancer screening experience: CT appearance, growth rate, location, and histologic features of 61 lung cancers. Radiology. 2007;242(2):555-62.

12. Mahoney MC, Shipley RT, Corcoran HL, Dickson BA. CT demonstration of calcification in carcinoma of the lung. AJR. 1990;154(2):255-8. 